\title{
ROOT DENSITY ANALYSIS AND WAVE ATTENUATION ABILITY OF RHIZOPHORA SPECIES AT KEMAMAN, TERENGGANU
}

\author{
Isfarita Ismail ${ }^{*}$, Mohd Lokman Husain ${ }^{2}$, Behara Satyanarayana ${ }^{2}$, Sulong Ibrahim ${ }^{2}$, Rozaimi Zakaria ${ }^{3}$ \\ ${ }^{1}$ Borneo Marine Research Institute, Universiti Malaysia Sabah, Jalan UMS, 88400, Malaysia. \\ ${ }^{2}$ Institute of Oceanography and Environment, Universiti Malaysia Terengganu, 21030 Kuala Terengganu, Malaysia \\ ${ }^{3}$ Faculty of Science and Natural Resources, Universiti Malaysia Sabah, Jalan UMS, 88400, Malaysia \\ *Corresponding author e-mail: isfarita@vahoo.com
}

This is an open access article distributed under the Creative Commons Attribution License, which permits unrestricted use, distribution, and reproduction in any medium, provided the original work is properly cited.

\section{ARTICLE DETAILS}

\section{Article History:}

Received 04 January 2019 Accepted 19 February 2019

Available Online 27 February 2019

\section{ABSTRACT}

The root density analysis and wave reduction ability of Rhizophora species was investigated at Pulau Sekepeng, Kemaman (Terengganu) in Peninsular Malaysia. A $12 \mathrm{~m}$ transect for Rhizophora species was set up inside the mangrove forest from the vegetation's edge. Many fishing boats pass through the estuary, each producing a set of waves in their wakes. Based on observations, the effect of vertical and horizontal variations in vegetation density on wave attenuation was analyzed. It is found that the vegetation density decreases with increasing distance inside the mangrove forest and it also decreases with increasing vertical height of mangrove trees. The average wave reduction increases with increasing distance inside the mangrove forest. Also, the wave reduction decreases with increasing water level. From this study it is concluded that the wave reduction ranged from as low as $3.27 \%$ to as high as $20.66 \%$, the average reduction being $11 \%$.

\section{KEYWORDS}

Wave attenuation, vegetation density, Pulau Sekepeng, Rhizophora sp., Kemaman (Terengganu), Peninsular Malaysia.

\section{INTRODUCTION}

Mangrove forests are one of the world's most threatened tropical ecosystems. Threats to mangrove forests include: clearing, over harvesting, overfishing, destruction of nearby coral reefs, etc. Also, mangrove forests require stable sea levels for long term survival. They are therefore extremely sensitive to current rising sea levels caused by global warming and climate change. In the mangrove forest, periodic tides and coastal currents change the chemical, physical and biological characteristics of their environment. Worldwide there are 15.8 million hectares of mangroves, but these are depleting at a rate of 2 to $8 \%$ per year in the world [1]. In Peninsular Malaysia, the total extent of mangrove forests is about $103,203.11$ ha. Out of the total, about $88,406.61$ ha or $85.6 \%$ is gazetted as Permanent Forest Estates (PFEs) while the remaining $14,796.5$ ha (14.4\%) is designated as state land mangroves [2].

Mangrove forests serve many useful purposes including providing habitat to many plant and animal species, acting as nursery ground, production of charcoal, fashion fish traps, boat construction, and are increasingly valued for eco-tourism ventures [3-5]. Another most important ecological significance of mangrove vegetation is its ability to trap the sediments by which shore erosion is controlled.

The quantitative effects of Rhizophora stylosa and Kandelia kandel on the reduction of sea waves was earlier studied respectively [6,7]. While a group research investigated the wave reduction in a mangrove area on the Iriomote Island in Japan, the researcher focused the study of wave attenuation in the region of Tong King delta, Vietnam [6,7]. Also, a studied the effect of Rhizophora sp. on the reduction of sea waves using a mathematical model at the Townsville (Australia) and the Iriomote Island (Japan) [8]. They found that the rate of wave energy attenuation depends on the density of the mangrove forest, diameter of mangrove roots and trunks. Later, some researcher discussed the characteristics of wave reduction due to the drag force of Sonneratia sp. at the Vinh Quang coast in northern Vietnam [9]. The rate of reduction of sea waves in this area changed with the tidal phase and depended on the incident wave height. Some researchers discussed the wave reduction due to the drag force for Kandelia kandel in the Red River Delta, Vietnam [10]. The incoming waves are reduced in height due to bottom friction and the wave reduction decreases with increasing water depth.

In view of the above studies, this paper focuses on the root density analysis of Rhizophora species and its ability on the wave attenuation at Kemaman Terengganu. For this purpose we have chosen a study site at Pulau Sekepeng having Rhizophora sp. in order to investigate the reduction of waves generated by the passage of fishing boats in the channel. The main objective of this paper is to quantify the percentage of wave reduction by Rhizophora sp. at Kemaman, Terengganu, and to determine the relationship between wave attenuation ability and vegetation density.

\section{METHODOLOGY}

2.1 Study area 
The study site is located in Pulau Sekepeng mangrove area which is situated in the district of Kemaman, Terengganu (latitude $4^{\circ} 13^{\prime} 50.43^{\prime \prime} \mathrm{N}$ and longitude $103^{\circ} 25^{\prime} 54.52^{\prime \prime} \mathrm{E}$ ). This area is in the Kemaman Permanent Forest Reserve (KPFR) of Peninsular Malaysia. The main drainage for the mangrove is primarily due to the tidal flow channeled through the Kemaman river estuary and the annual flooding during the north-east monsoon season.

The Pulau Sekepeng mangrove area belongs to the estuarine forest type. The dominant mangrove species in the swamp are Rhizophora sp., with some patches of Avicennia sp., Bruguiera sp., Sonneratia sp. and Ceriops. The sampling transect within the study site is located in the Rhizophora zone. The Figure 1 shows the map of Pulau Sekepeng in the district of Kemaman, Terengganu. The Kemaman river estuary is a major navigational channel for fishing vessels that ply particularly during high tides. Firstly, we surveyed the area at Kemaman Forest Researve to find the best site for Rhizophora sp. After a detailed survey the best transect for this species was found, which was $12 \mathrm{~m}$ long inside the mangrove forest from the vegetation's edge (refer Figure 2). The site is about $3 \mathrm{~km}$ from the mouth of the estuary which lies at the northern end of the Kemaman river.

Along the transect we chose 12 locations, each $1 \mathrm{~m}$ apart. The first location at the vegetation's edge has been designated as plot 0 , while plot 1 refers to the next location $1 \mathrm{~m}$ inside the mangrove, and so on. In this study 12 sets of readings were recorded. For reading 1 , the water loggers were set up at plot 0 and 1 ; for reading 2 , they were set up at plot 0 and 2 ; and so on. For each reading, the data were collected for one tidal cycle during the spring tide.

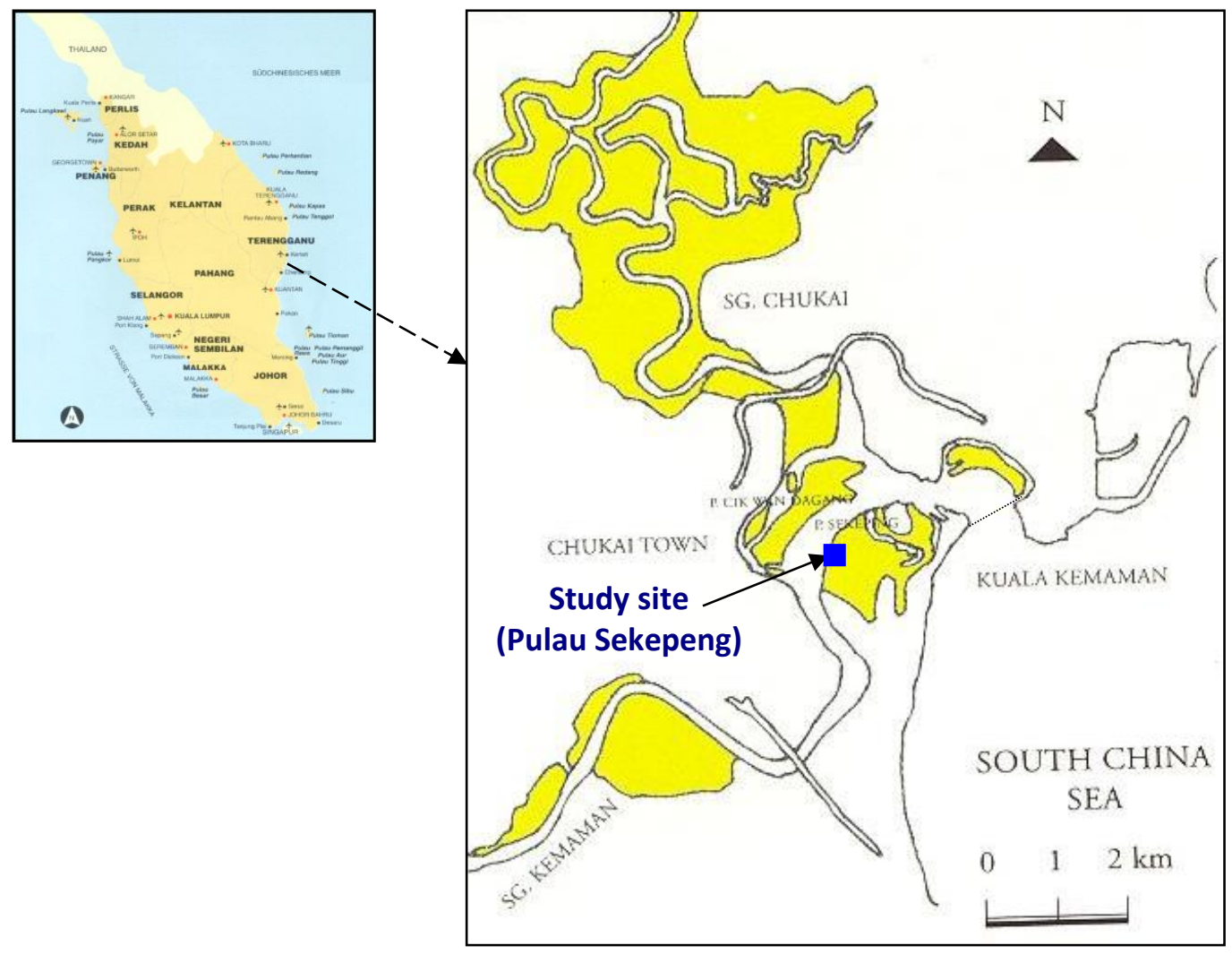

Figure 1: Map of Pulau Sekepeng, Kemaman

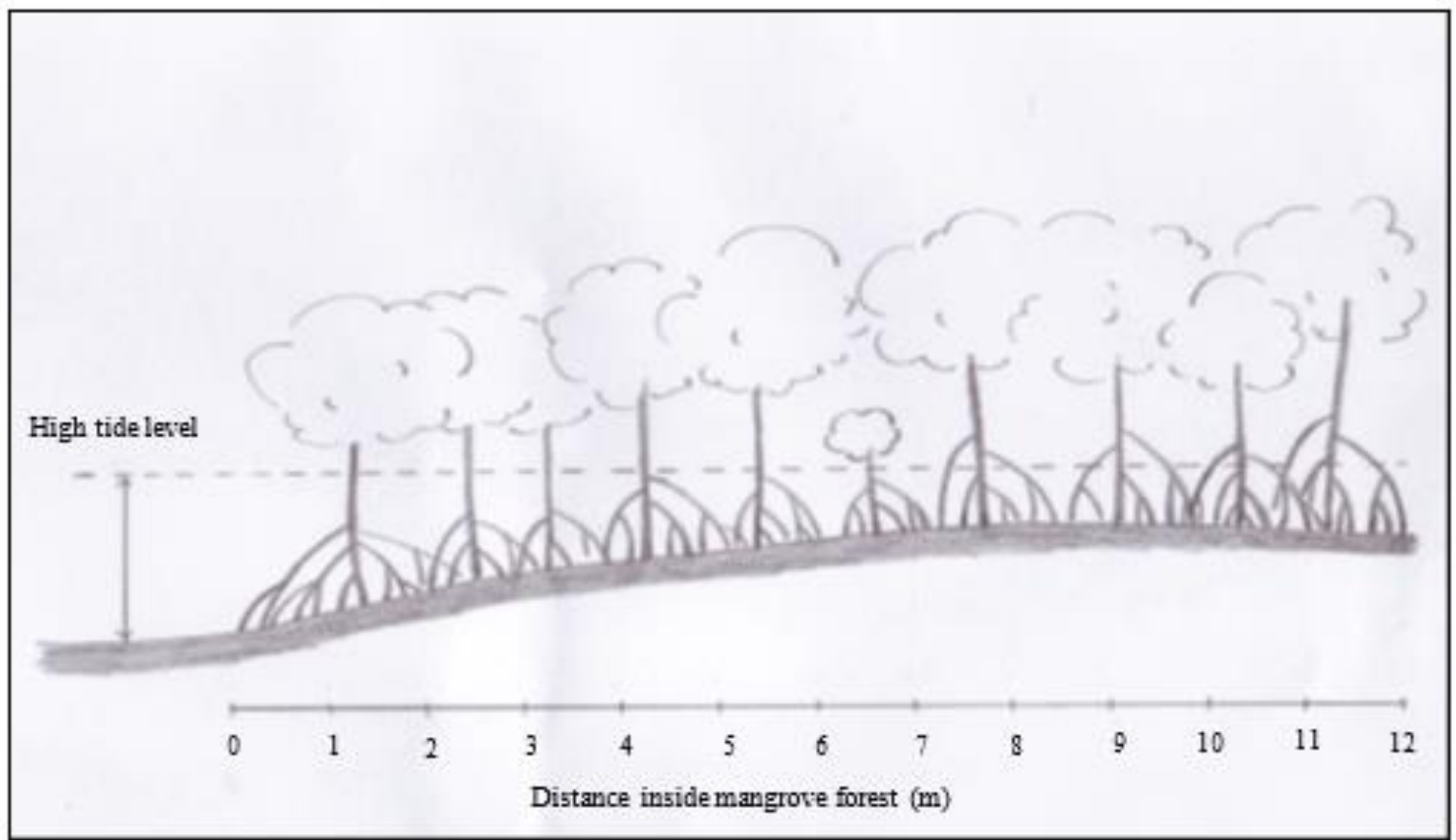

Figure 2: Transect of idealized Rhizophora sp. at Kemaman, Terengganu 


\subsection{Observation of root density data}

To measure the root density a series of $1 \mathrm{~m}^{2}$ area are designated all along the transect line from the front to the back of the mangrove. Each root and stem of the vegetation which falls within the $1 \mathrm{~m}^{2}$ area is measured for their diameter at every $20 \mathrm{~cm}$ level from the bottom upwards. Measurements are made up to the height of $1 \mathrm{~m}$ since the level of the high tide inside the selected mangrove site is found to be approximately $1 \mathrm{~m}$.
To measure the root density, calipers were used while the height of the root was measured with a measuring tape. The roots and stems are assumed to be cylindrical in shape. Thus, using the equation: $\mathrm{D}=\pi r^{2} \mathrm{~h}$

where $\pi=3.142, r=$ radius and $h=$ height, the volume of the roots/ stems (root density) are obtained within each area. Figure 3 shows the 1 $\mathrm{m}^{3}$ region within a Rhizophora sp. transect and the $20 \mathrm{~cm}$ vertical layers for measuring root densities.

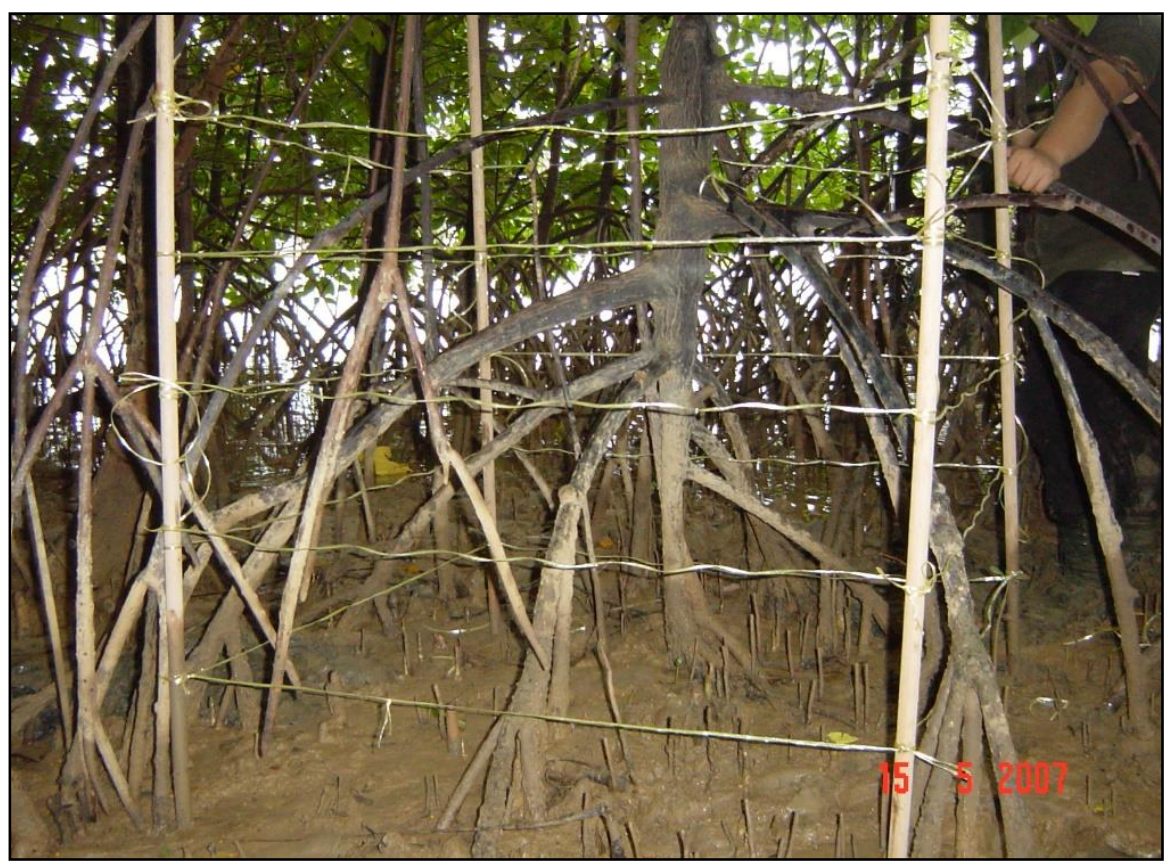

Figure 3: One cubic meter region within a Rhizophora sp. transect and the $20 \mathrm{~cm}$ vertical layers for measuring root densities.

\subsection{Wave data sampling}

Wave height data were collected using Boart Longyear Interfels water logger (Boart Longyear, Germany). At any plot along the transect, a water logger is set vertically at the bottom of the mangrove tree by securing it to its root/stem. During the course of wave data collection, many fishing boats pass through the area and would generate small waves. The wave fluctuations recorded by the water logger due to each passing boat is called a wave burst, which ride over the tidal wave and are captured by the water logger. The dates, readings and number of wave bursts recorded during the sampling are presented in Table 1 . For each reading, two water loggers were set up at two locations to sample the water level and associated parameters at 1 second interval. For example, for reading 1 , the two water loggers were set up at plot 0 and plot 1 while for reading 2 , the water loggers were fixed at plot 0 and plot 2 , and so on. In this study we have undertaken 12 sets of readings for plot 1 to 12 and the number of wave bursts in each 12 readings ranged from 0 to 9 .

Table 1: Sampling variability using two wave gauges for Rhizophora sp. at Kemaman, Terengganu.

\begin{tabular}{|c|c|c|c|c|c|c|c|c|c|c|c|c|c|c|c|}
\hline \multirow[b]{2}{*}{ Date } & \multirow[b]{2}{*}{ Reading } & \multirow{2}{*}{$\begin{array}{c}\text { No of } \\
\text { wave burst }\end{array}$} & \multicolumn{13}{|c|}{ Plot } \\
\hline & & & 0 & 1 & 2 & 3 & 4 & 5 & 6 & 7 & 8 & 9 & 10 & 11 & 12 \\
\hline $27 / 12 / 2007$ & 1 & 2 & $\sqrt{ }$ & $\sqrt{ }$ & & & & & & & & & & & \\
\hline $15 / 2 / 2008$ & 2 & 9 & $\sqrt{ }$ & & $\sqrt{ }$ & & & & & & & & & & \\
\hline $23 / 11 / 2007$ & 3 & 3 & $\sqrt{ }$ & & & $\sqrt{ }$ & & & & & & & & & \\
\hline $14 / 9 / 2007$ & 4 & 5 & $\sqrt{ }$ & & & & $\sqrt{ }$ & & & & & & & & \\
\hline $2 / 10 / 2007$ & 5 & 6 & $\sqrt{ }$ & & & & & $\sqrt{ }$ & & & & & & & \\
\hline $14 / 9 / 2007$ & 6 & 5 & $\sqrt{ }$ & & & & & & $\sqrt{ }$ & & & & & & \\
\hline $16 / 2 / 2008$ & 7 & 4 & $\sqrt{ }$ & & & & & & & $\sqrt{ }$ & & & & & \\
\hline $21 / 2 / 2008$ & 8 & 0 & $\sqrt{ }$ & & & & & & & & $\sqrt{ }$ & & & & \\
\hline $22 / 2 / 2008$ & 9 & 1 & $\sqrt{ }$ & & & & & & & & & $\sqrt{ }$ & & & \\
\hline $15 / 9 / 2007$ & 10 & 6 & $\sqrt{ }$ & & & & & & & & & & $\sqrt{ }$ & & \\
\hline $29 / 2 / 2008$ & 11 & 2 & $\sqrt{ }$ & & & & & & & & & & & $\sqrt{ }$ & \\
\hline $28 / 2 / 2008$ & 12 & 5 & $\sqrt{ }$ & & & & & & & & & & & & $\sqrt{ }$ \\
\hline
\end{tabular}

Figure 4 shows a water logger set up during the data collection. The water loggers are left for one tidal cycle after which they are retrieved and the data is downloaded onto a computer. The data is then analyzed further for mean wave height, and subsequently attenuation, as the equipment is moved to other locations inside the mangrove. 


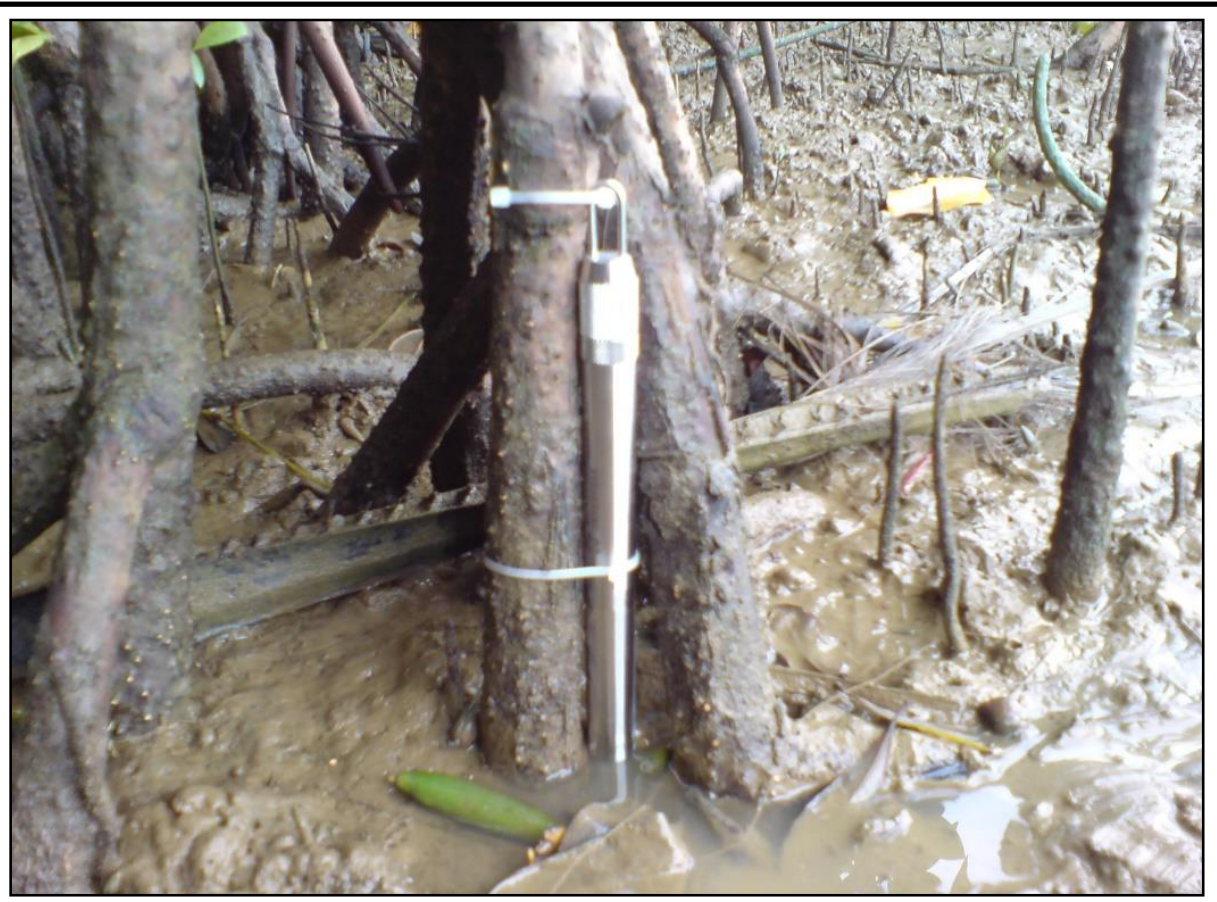

Figure 4: Water logger set up during the data collection at Kemaman, Terengganu

One of the wave bursts are shown in Figure 5. Each burst contains a set of waves. Wave heights of less than $2 \mathrm{~cm}$ are taken as water movement due to the wind, and hence not considered as boat induced waves [10]. Thus, only water levels of more than $2 \mathrm{~cm}$ are considered in the computation of wave height.

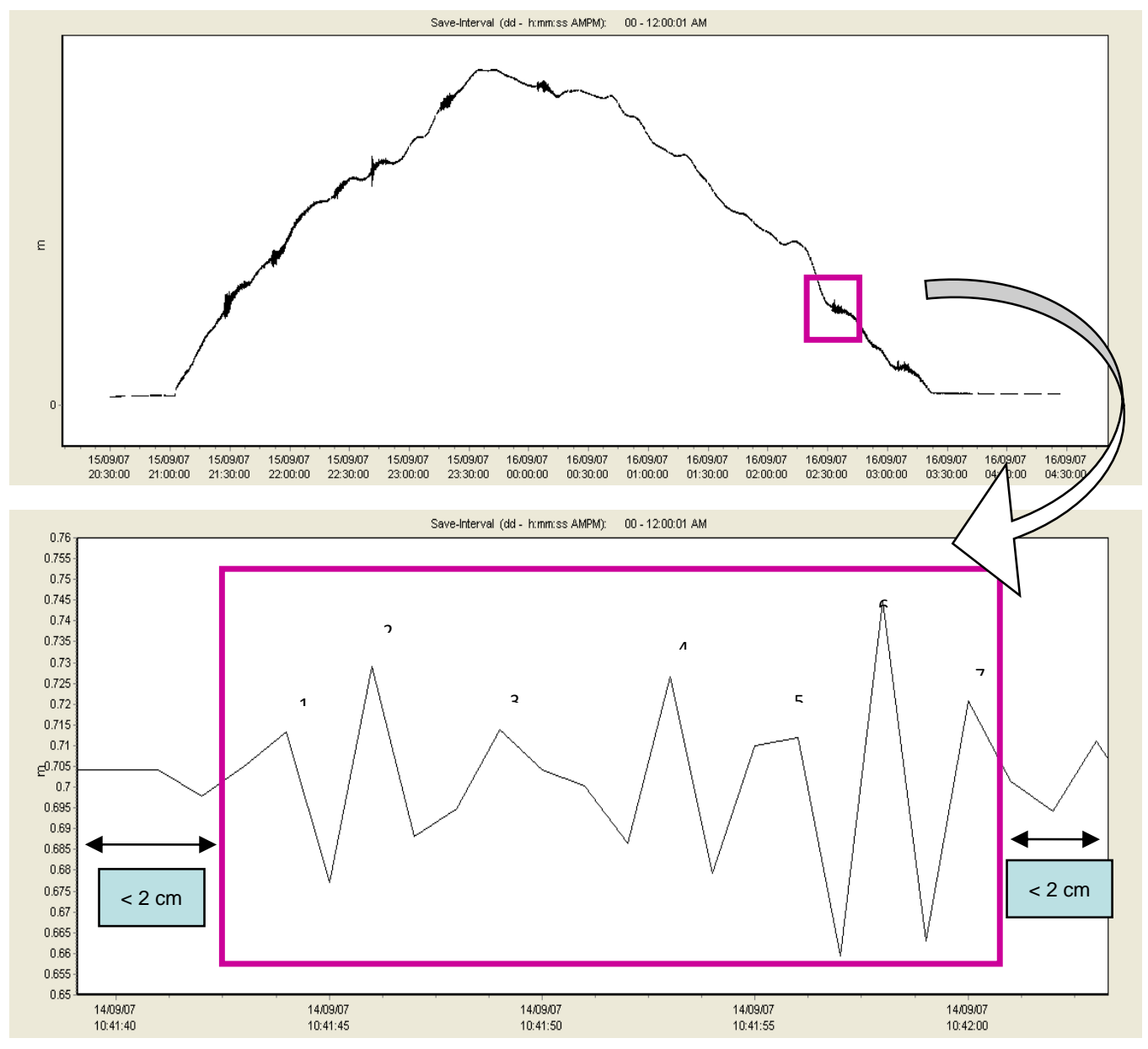

Figure 5: An example of a wave burst and identification of associated waves

After identifying the waves 1 to 7 in Figure 5, their mean height was used to calculate the wave reduction. Following the wave reduction is given by

$$
R=\frac{H_{S}-H_{L}}{H_{S}},
$$

where, 
$R=$ reduction, percentage reduction $=\mathrm{Rx} 100$

$H_{S}=$ wave height in front of mangrove (plot 0)

$H_{L}=$ wave height at a location' L' inside the mangrove forest

\section{RESULTS AND DISCUSSION}

3.1 Root density variability
The root density data are computed from the front to the back of the mangrove along the transect. All roots and stems from within a $1 \mathrm{~m} \times 1 \mathrm{~m}$ base up to a height of $1 \mathrm{~m}$ are measured for its length and diameter. The measured root data are reported in terms of volume (root density) in five vertical layers, divided into $20 \mathrm{~cm}$ each, from the bottom to the top. At the study site the vegetation is found to be fronting the riverbank. The root density measurement for each vertical $(20 \mathrm{~cm})$ layer and $1 \mathrm{~m}^{2}$ horizontal plot are given in Table 2 below.

Table 2: Root density $\left(\mathrm{cm}^{3}\right)$ for each $20 \mathrm{~cm}$ layer at every plot from the front to the interior of the mangrove forest

\begin{tabular}{|c|c|c|c|c|c|c|}
\hline $\begin{array}{l}\text { Plot along } \\
\text { transects }\end{array}$ & $\begin{array}{c}\text { Layer } \\
0- \\
20 \mathrm{CM} \\
\end{array}$ & 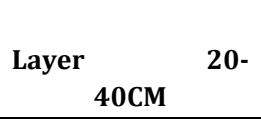 & $\begin{array}{c}\text { Layer } 40 \text { - } \\
60 \mathrm{CM}\end{array}$ & $\begin{array}{c}\text { Layer } 60 \text { - } \\
80 \mathrm{CM} \\
\end{array}$ & $\begin{array}{cc}\text { Layer } & 80- \\
& \\
& \end{array}$ & $\begin{array}{c}\text { Averag } \\
\text { e } \\
\left(\mathrm{cm}^{3}\right)\end{array}$ \\
\hline 1 & 8470.59 & 6707.22 & 4206.15 & 7433.82 & 4486.93 & 6260.94 \\
\hline 2 & 5050.06 & 4568.95 & 4087.15 & 3843.91 & 1514.01 & 3812.82 \\
\hline 3 & 3543.04 & 1959.42 & 2391.62 & 1483.32 & 1080.31 & 2091.54 \\
\hline 4 & 1609.72 & 952.94 & 436.88 & 344.21 & 0 & 668.75 \\
\hline 5 & 1574.01 & 1001.58 & 931.15 & 508.79 & 235.36 & 850.18 \\
\hline 6 & 4044.46 & 2640.09 & 1913.42 & 1427.89 & 876.24 & 2180.42 \\
\hline 7 & 2201.84 & 2629.14 & 1825.63 & 897.27 & 0 & 1510.78 \\
\hline 8 & 799.85 & 918.5 & 329.85 & 215.5 & 0 & 452.74 \\
\hline 9 & 2244.09 & 1132.15 & 568.99 & 1733.13 & 1879.59 & 1511.59 \\
\hline 10 & 999.81 & 1179.2 & 128.7 & 32.33 & 290.48 & 526.10 \\
\hline 11 & 2017.61 & 1110.51 & 841.25 & 336.9 & 477.19 & 956.69 \\
\hline 12 & 1491.3 & 407.95 & 426.85 & 292.42 & 211.28 & 565.96 \\
\hline Average & 2837.2 & 2100.64 & 1507.3 & 1545.79 & 920.95 & \\
\hline
\end{tabular}

The Table 2 shows that, in general, the root density is highest in the bottom layer and gradually less towards the top layer. This is expected of the Rhizophora sp. as their root network is of the cone shaped type. It may be noted that at some plots the $80-100 \mathrm{~cm}$ layers do not have roots or stems because no root reach the height above $80 \mathrm{~cm}$.

The root system of the mangrove is one of the primary components that help in the reduction of waves as mentioned [9]. The analyses of root density variation on a horizontal and vertical basis for Rhizophora sp. are discussed below.

In general, the Rhizophora mangrove near a water front is dense while the density decreases towards the back mangroves. The front mangroves occupy lower grounds compared to the areas further along the transect and as such receive more tidal inundations for longer period of time. Also, the sediment deposition at the front mangroves is much higher compared to the areas towards the back mangroves as reported [2]. Hence, the front mangroves receive more nutrients and are thus much healthier. In addition, given the deeper and longer duration of tidal inundation, the front mangroves grow higher. They need more roots in order to breathe and to be more stable, thus accounting for a higher density of roots and stems.

Figure 6 shows the correlation between root density and distance for Rhizophora species in the current study. It is found that the root density decreases with increasing distance inside the swamp. The root density is highest at plot 1 (first $1 \mathrm{~m}$ from the vegetation's edge) because the plants are healthy having many roots/stems. For root density vs. distance, the correlation coefficient is found to be -0.71 . Thus, there is a strong negative relationship between the root density and the distance inside the mangrove.

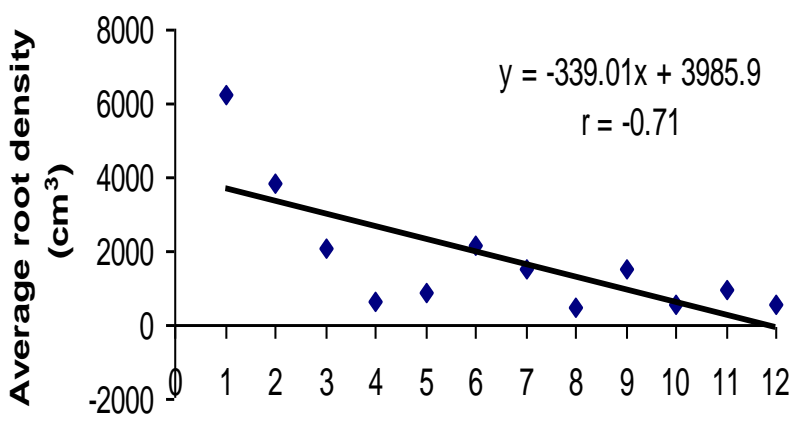

Plot/distance inside mangrove forest ( $\mathrm{m}$ )

Figure 6: Correlation between average root density and distance inside mangrove forest

A relation between average root density and vertical layer (each $20 \mathrm{~cm}$ 
layer) all along the transect shows that the root density decreases with increasing vertical layers (Figure 7). The base layer $(0-20 \mathrm{~cm})$ closest to the ground is dense because most type of roots and stems can be found in this layer. Additionally, Rhizophora has a cone shaped root system where roots branch from the stem and spread downwards. This type of root system would be denser at the bottom and less dense as it tapers upward.
In this study such a trend is found all along the transect line. Here, the correlation coefficient, $r=-0.96$, for root density vs. vertical layers. This indicates that there is a strong negative relationship between the root density and the vertical levels, the average root density decreases as the vertical levels increase.

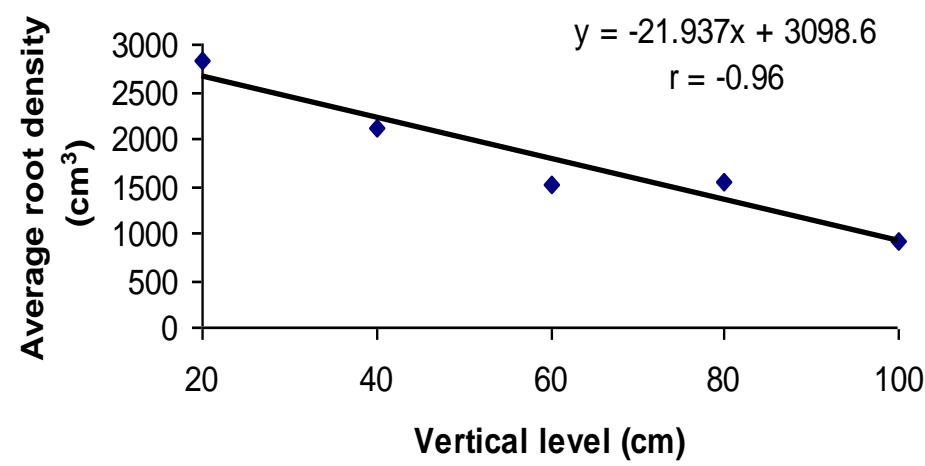

Figure 7: Correlation between average root density and vertical levels $(20 \mathrm{~cm}$ layers $)$

\subsection{Wave reduction}

Wave attenuation is the decline in the wave amplitudes as the waves pass through a mangrove forest. Table 3 shows the percentage of wave reduction for readings 1 to 12 for Rhizophora sp. at Kemaman. Wave reduction ranged from as low as $3.27 \%$ to as high as $20.66 \%$, the average amount of reduction being $11 \%$. It may be noted from eq. (1) that an increase in $\mathrm{R}$ (wave reduction) from one plot to the other correspond to a decrease in the wave height.

Table 3: Wave reduction for reading 1 to 12 for Rhizophora sp.

\begin{tabular}{|c|c|}
\hline Reading & Average Reduction (\%) \\
\hline 1 & 3.267 \\
\hline 2 & 12.181 \\
\hline 3 & 8.057 \\
\hline 4 & 16.865 \\
\hline 5 & 10.466 \\
\hline 6 & 9.817 \\
\hline 7 & 12.014 \\
\hline 8 & $\mathrm{~N} / \mathrm{A}$ \\
\hline 10 & 20.658 \\
\hline 11 & 10.52 \\
\hline 12 & 7.379 \\
\hline Average & 20.174 \\
\hline
\end{tabular}

N/A - Data not available

As the wave moves inside the mangrove and meets the first line of mangrove stems and roots, some of the energy would be dissipated before it continues its journey forward towards the back mangroves. The Figure 8 shows the relation between average wave reduction and distance inside Rhizophora sp. It may be seen that overall the percentage wave reduction increases with increasing distance inside the mangrove forest. The correlation coefficient between wave reduction and distance inside mangrove forest is 0.31 . This indicates a weaker relationship between the wave reduction and the distance inside the mangrove.

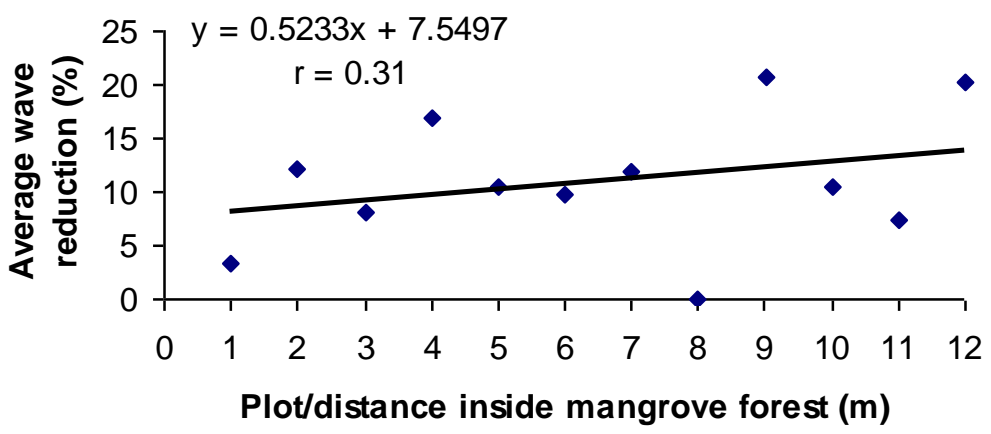

Figure 8: Correlation between average wave reduction and distance inside mangrove forest 
A relation between average wave reduction and the $20 \mathrm{~cm}$ water levels for Rhizophora sp. is shown in Figure 9. The wave reduction decreases with increasing water level. It is seen from the figure that the wave attenuation is more pronounced in $(0-20 \mathrm{~cm})$ level because in this level there are plenty of stilt roots $[9,10]$. The correlation coefficient between wave reduction and vertical levels is -0.79 . Thus, there a strong negative relationship between the wave reduction and the vertical levels.

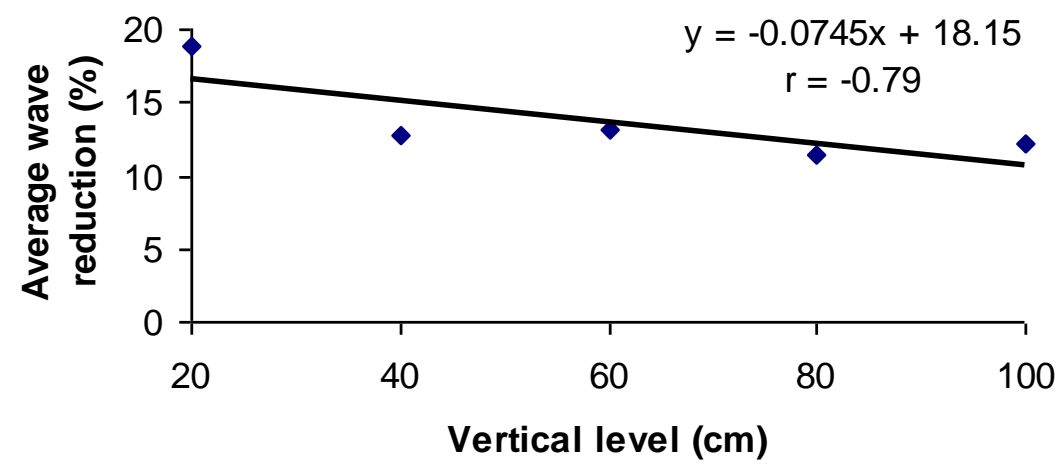

Figure 9: Correlation between average wave reduction and vertical levels $(20 \mathrm{~cm}$ layers)

\section{CONCLUSION}

The study investigates the wave reduction in a mangrove forest having Rhizophora sp. at Kemaman, Terengganu. This study analyses both root density and wave attenuation on a horizontal and vertical basis. From root density measurements it is found that the average root density decreases with increasing distance inside the mangrove. Also, the root density decreases with increasing vertical layers. The Rhizophora sp. near a water front is dense compare with the back of the mangrove. The front mangroves occupy lower grounds compared to the areas inside the mangrove forest and receive more tidal inundations for longer period of time. They also receive more nutrients and are much healthier.

As the waves move inside the mangrove forest, they meet the stems and roots and the wave gets dissipated. It is found that the average wave reduction increases with increasing distance inside the mangrove while it decreases with increasing water level. Also, a relation between root density and wave reduction vs. distance inside the mangrove shows that the root density decreases as the wave reduction increases inside the mangrove forest. However, the two variables decrease with increasing vertical height. It may be noted that the correlation coefficient between the root density and wave reduction vs. horizontal distance is smaller compared to the vertical levels.

Based on the measurements and subsequent analysis it is found that Rhizophora is a good species for wave attenuation compared to other species like Bruguiera and Avicennia which have low root densities. It was found that Rhizophora can attenuate the waves with about $11 \%$ overall reduction in the wave height.

\section{ACKNOWLEDGEMENTS}

This study was supported by an e - Science funding from MOSTI. The authors would like to thank the facilities provided by the Institute of Oceanography, Universiti Malaysia Terengganu. We are also thankful to the referee for making some useful suggestions.

\section{REFERENCES}

[1] Spalding, M., Blasco, F., Field, C.D. 1997. World mangrove atlas. The International Society for Mangrove Ecosystem (ISME). Cambridge Okinawa: Samera Publishing Co., 178 pp.

[2] Lokman, M.H. 2004. Exploring the Interface: The Enigmatic Mangroves. KUSTEM Inaugural Lecture, 8, 1 - 22.

[3] Cannicci, S., Burrows, D., Fratini, S., Lee, S.Y., Smith T.J. III, Offenberg, J., Dahdouh - Guebas, F. 2008. Faunistic impact on vegetation structure and ecosysyem function in mangrove forests: a review. Aqut. Bot., 89, $186-$ 200.

[4] Nagelkerken, I., Blaber, S., Bouillon, S., Green, P., Haywood, M., Kirton, L.G., Meynecke, J.O., Pawlik, J., Penrose, H.M., Sasekumar, A., Somerfield, P.J. 2008. The habitat function of mangroves for terrestrial and marina fauna: a review. Aquat. Bot., 89, $155-185$.

[5] Snedaker, S.C., Snedaker, J.G. 1984. The mangrove ecosystem: research methods. UNESCO, Paris.

[6] Magi, M., Mazda, Y., Ikeda, Y., Kurokawa, T. 1996. Wave reduction in a mangrove area near of the mouth of Shiira River on the Iriomote Island, Japan. Mangrove Sci., 1, 35 - 42. (in Japanese with English abstract).

[7] Mazda, Y., Magi, M., Kogo, M., Hong, P.N. 1997. Mangroves as a coastal protection from waves in the Tong King Delta, Vietnam. Mangrove Salt Marshes, 1(2), 127 - 135.

[8] Massel, S.R., Furukawa, K., Brinkman, R.M. 1999. Surface wave propagation in mangrove forests. Fluid dynamics Research, 24, 219 - 249. [9] Mazda, Y., Magi, M., Ikeda, Y., Kurokawa, T., Asano, T. 2006. Wave attenuation in a manrove forest dominated by Sonneratia sp. Wetlands Ecol. Manage, 14, 365 - 378.

[10] Quartel, S., Kroon, A., Augustinus, P.G.E.F., Van Santen, P., Tri, N.H. 2007. Wave attenuation in coastal mangroves in the Red River Delta, Vietnam. Journal of Asian Earth Sciences, 29, 576 - 584. 